\title{
The use of electronic information resources for academic research by postgraduate students at Delta State University, Abraka, Nigeria
}

\author{
Faith Ashinedu Okite-Amughoro ${ }^{1}$, Lefose Makgahlela ${ }^{2}$ and Solomon Bopape ${ }^{3}$ \\ Nedufaith@yahoo.com, Lefose.Makgahlela@ul.ac.za and \\ Solomon.Bopape@ul.ac.za ORCID ID: orcid.org/0000-0003-3389-2378
}

\author{
Received: 15 March 2014 \\ Accepted: 7 December 2014
}

\begin{abstract}
This study used a structured questionnaire to investigate the usage of Electronic Information Resources (EIR) for academic research by 150 postgraduate students at Delta State University, Abraka, Nigeria. Interviews with some students and selected individuals at the institution were also conducted. The study looked into whether postgraduate students had access to EIR; whether they knew how to use computers in order to have access to EIR; the extent to which they knew and were aware of EIR; the current status of EIR at their institution; how often they used these resources for academic research purposes; and the challenges that they encountered in using these resources. The findings of the study show that postgraduate students at Delta State University are aware of the existence of EIR, but the optimal use of these resources is hampered by limited access to some EIR due to lack of information searching skills, limited space, low bandwidth and erratic power supply. It is, therefore, recommended that the institution should provide adequate space, enough power supply and should address some of the issues hindering equitable access to these resources. The development of an institutional repository and the use of open access resources will also improve access to scientific and electronic information by postgraduate students at the institution.
\end{abstract}

Keywords: Electronic Information Resources, EIR, electronic databases, academic research, postgraduate students, tertiary institutions, university libraries, Delta State University, Abraka, Nigeria

\section{Introduction}

In the past, postgraduate research in tertiary institutions was dominated by the use of printed materials as primary sources of information. But today, advances in Information Technology (IT) have changed the way in which information for academic research is accessed and disseminated (Ndinoshiho 2010). The academic world has reached an era where printed materials for research are being replaced by electronic materials that can be accessed via the internet. Tella, Owolabi and Attama (2009) state that it is no longer surprising that, in this digital age, many libraries in tertiary institutions are connected to the internet or have plans to get connected soon. Academic libraries are increasingly taking advantage of Information and Communication Technologies (ICTs) to provide improved access to EIR to their users. The availability of information in electronic media has, as such, created opportunities for global access to information, enhanced the speed of service, increased the number of users served, increased the quantity and exhaustiveness of information provided, and offered new and exciting opportunities for postgraduate students to find information related to their research areas (Varghese 2008).

There is no doubt that the development of EIR in university libraries in Nigeria will facilitate access to vast collections of digital books and electronic journals for postgraduate students (Afolabi 2007). According to Okon (2010), although the internet has, in the past decade, been integrated into major academic sectors in Nigerian universities, there still exists a digital divide or inequitable access to electronic information in the system. Most university libraries in Nigeria have yet to adopt a policy of providing equitable internet access to their postgraduate students. Postgraduate students have, in fact, mostly been affected by the inequitable access to the internet at these universities.

The adoption and diffusion of EIR in university libraries in Nigeria has not been as rapid and smooth as in advanced information societies, where EIR are seen as key to information access and use. Afolabi (2007) notes that the dearth of current and up-to-date information for postgraduate research in Nigerian university libraries has been a major source of concern to both the library management and the research community in the country. The aim of this study is to investigate the use of EIR for academic research by postgraduate students at Delta State University, Abraka, Nigeria. The study demonstrates the extent to which postgraduate students at Delta State University, Abraka, utilise EIR to pursue their academic research.

1. Faith Ashinedu Okite-Amughoro is a PhD student in the Information Studies Programme, University of Kwazulu Natal

2. Lefose Makgahlela is a Lecturer for the Programme of Information Studies in the School of Languages and Communication Studies: Department of Media Studies at the University of Limpopo

3. Dr Solomon Bopape is a Senior Lecturer for the Programme of Information Studies in the School of Languages and Communication Studies: Department of Media Studies at the University of Limpopo 
To achieve the above aim, the objective of the study was to investigate the following at the Delta State University, Abraka, Nigeria:

- $\quad$ The current status and accessibility of EIR by postgraduate students;

- $\quad$ The level of awareness and knowledge regarding EIR among postgraduate students;

- $\quad$ The competence and ease of usage of EIR by postgraduate students;

- $\quad$ The frequency of usage of EIR by postgraduate students.

\section{Literature Review}

As noted by Adegbore (2011), databases and electronic journals are used by academics for both teaching and research, among other uses. Academics have indicated satisfaction with their use of electronic resources and have committed themselves to the continuous use of these resources because this leads to better research and enhanced scholarly communication. Digital technology has changed the academic environment. It has not only influenced the teaching style and research methods of academics, but also affected the source and means of teaching and conducting research (Tahir, Mahmood \& Shafique 2010). Accordingly, today academic libraries provide various online services to their users throughout the world. One of the popular services is the provision of access to online databases consisting of electronic resources such as e-journals, e-books, and e-theses and dissertations.

There has been an exponential growth in electronic resources, and academic libraries have been spending a substantial amount of their annual budgets on subscriptions to online databases. Electronic resources can provide many advantages over traditional print-based resources (Tyner 2014; Ji, Michaels \& Waterman 2014). Electronic resources can contain current information because they are able to be updated frequently; they offer advanced search capabilities; they offer flexibility in the storage of search results; and they allow access to information without the restrictions of time and location (Togia \& Tsigilis 2009). Hemminger et al. (2007) note that there has been a dramatic shift towards the use of electronic communication of scientific scholarly information since the beginning of the twenty-first century. Unsurprisingly, the widespread availability of web-based electronic journals has been the primary driver of change.

The academic sector has not been left out of the dramatic shift towards the use of electronic communication. According to Golwal, Sonwane and Vaishnav (2008), electronic resources have become the most popular tools for research and academic activities. Okello-Obura and Magara (2008) state that the major objective of the adoption of eresources is the facilitation of access to international information resources via the internet, as well as the timely dissemination of both local and international research output. This is because researchers still need information, mainly for reviewing their existing knowledge on given topics, and for keeping themselves abreast of new developments. Information is also needed for solving topical problems and for brainstorming ideas for new research.

Several studies across the world have suggested that the use of electronic resources could enhance - and has enhanced - the efficiency, effectiveness and quality of education, learning and the research process. For instance, Gardner, Juricek and Xu (2008) conducted a survey of electronic information in the top one hundred colleges and universities in the United States of America, and discovered that the quality of circulation and the ability to support teaching and research have been improved tremendously. Dilek-Kayaoglu (2008) examined the usage of electronic resources by an academic community in Istanbul, Turkey: the majority of respondents supported the transition from print to electronic resources. So, the importance of electronic information cannot be over-emphasised because, as asserted by Liyi (2011), Ayoo and Lubega (2014), and Rioux (2014), electronic resources as an integral part of an institution's libraries and academic resources assist learning, teaching and research activities at colleges and universities.

Since information has become a commodity that should be quickly and easily found if researchers are to be productive and competitive, allocating funds to the development of library information systems and on electronic services and resources is crucial. Electronic access to scientific information is certainly one of the key factors in increasing the number of scientific publications by researchers (Kont 2010). However, Bako (2005) notes that less than 10\% of Nigerian university-based research is funded externally by foreign bodies, and the same percentage by the university research body. The idea of research as an academic activity for generating knowledge for economic development is yet to be fully appreciated in Nigeria by the ruling class, policy makers and university administrators. Currently, research at university is funded by graduate students, staff in training and academic staff, who themselves are poorly paid (Akpochafo 2009).

\section{Methodology}

This study adopted both quantitative and qualitative research approaches, which required the use of questionnaires and interviews respectively. Questionnaires were distributed to 150 postgraduate students in the faculties of Sciences, Social Sciences and Arts, at Delta State University, Abraka in Nigeria while the students were attending their block classes.

The questionnaire was tailored towards exploring the use of EIR by postgraduate students for academic research by determining whether or not the respondents had access to EIR, and whether or not they knew how to use the computers to access EIR. It was also important to determine the extent to which they knew about EIR, the current status of EIR at their institution, and how often they used those resources for academic research purposes. The questionnaires were collected immediately after they were completed. As a result, the researchers received a $100 \%$ response rate on the questionnaires distributed. 
The researchers also interviewed ten individuals. Eight of them were postgraduate students randomly selected by the researchers, and two were library staff members; one of the staff members was the head of ICT in the library. The interviewees were asked about the challenges that they face when trying to access EIR at the institution.

\section{Results and discussion}

The first question from the questionnaire was aimed at soliciting information about the accessibility of EIR by the postgraduate students at the institution in order to determine the types of EIR that the respondents could have access to. Figure 1, below, shows a total of $140(93 \%)$ respondents indicated that they have access to e-journals, whilst ten $(7 \%)$ of respondents do not have access to this type of EIR.

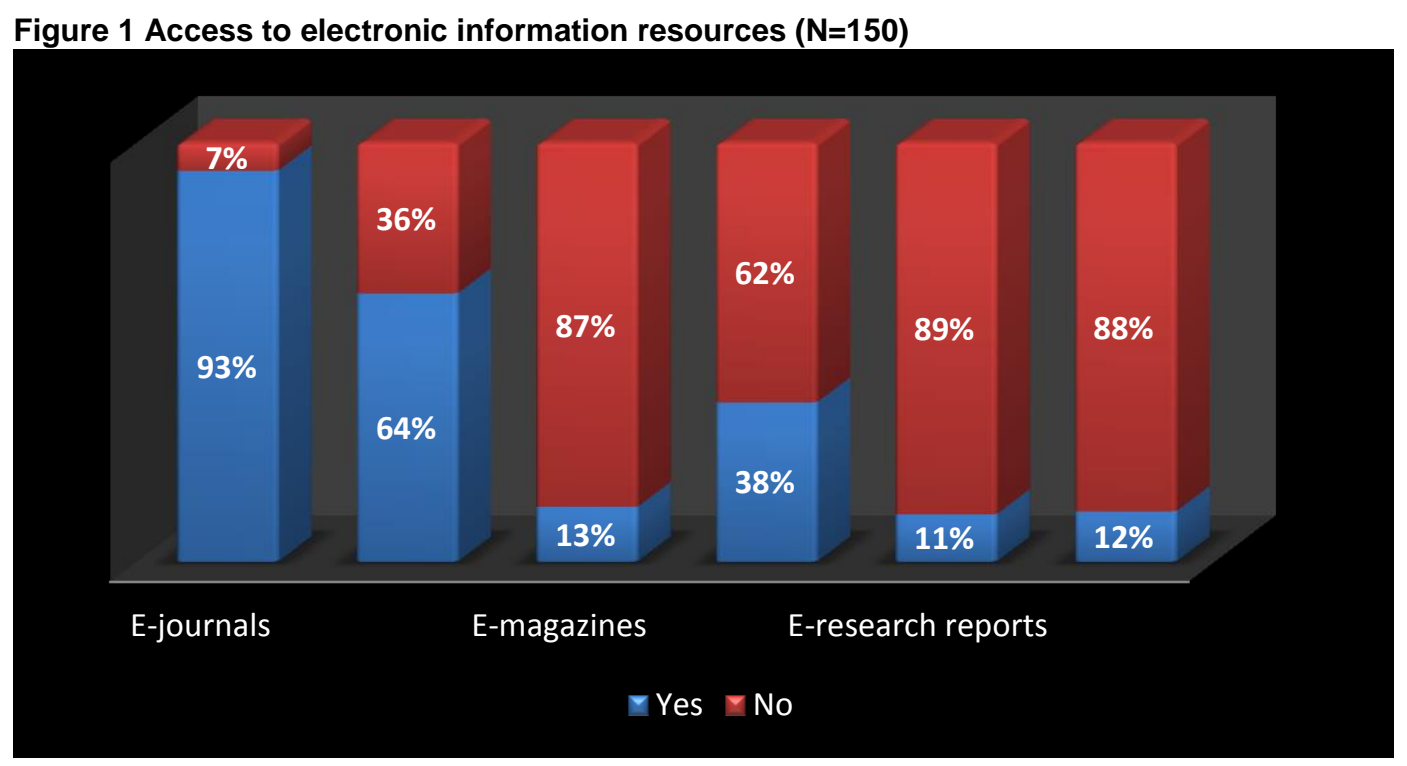

Ninety-six (64\%) of the participants gave positive responses about having access to e-books whilst fifty-four (36\%) respondents do not have access to this electronic resource. Most of the respondents gave negative responses about having access to e-magazines and e-theses at $130(87 \%)$ and ninety-three (62\%), respectively. This means that only twenty $(13 \%)$ participants could have access to e-magazines and fifty-seven (38\%) to e-theses and dissertations. Bibliographic databases that are in electronic format can be accessed by $132(88 \%)$ respondents, while eighteen (12\%) cannot access them.

These results indicate that the postgraduates had more access to e-journals and e-books, and minimal access to etheses, e-magazines and bibliographic databases. E-journals are searchable and easily accessibility irrespective of time and location, that is, even by those who are not within easy reach of the library. Hamade and Al-Yousef (2010) write that users, in general, prefer electronic journals because they make their work easier and give them the information they need. Rapid online access, and the ability to download, print, and send articles electronically are some of the top advantages of electronic journals for all user groups.

There are different types of access granted to different groups depending on their levels of subscription, which may allow access to abstracts only, or full texts. E-books, for example, are not as easily and quickly accessible as e-journals, but are portable, and make it easy to access an entire library collection at one's fingertips, depending on the conditions set out by the different e-book publishers. The low level of access to e-theses and e-magazines does not necessarily mean that these resources are not available, but rather that the postgraduate students do not know how to access them, or that they are not aware of their existence.

Therefore, in order to determine their level of awareness of EIR, respondents were asked to indicate the extent to which they knew about EIR. As indicated in Figure 2, two respondents indicated that their knowledge of these information resources is "to no extent", $107(71 \%)$ responded "to some extent" and forty-one $(27 \%)$ answered that their knowledge of information resources is "to a large extent". Most respondents, therefore, are aware of the existence of EIR at the institution. Similarly, in the study carried out by Ali (2005), highlighting the use of electronic information services (EIS) among the users of Indian Institute of Technology (IIT) library in New Delhi, India, data were collected from three hundred IIT library users. The results revealed that $95 \%$ of users were aware of EIS provided by the library. In the study conducted by Kindilchie and Samarraie (2008), when asked about e-resource use, faculty members responded that lack of familiarity with e-resources was the lowest-ranked problem.

There is a belief that users with little competency in the use of EIR are less likely to use those resources than those who are competent in their use. It is only through training that users can become competent in the use of ICTs in order to access EIR. The participants were therefore asked to show if they had or had not receive any training in the use of EIR. The results, in Figure 3, show that $101(67 \%)$ of the respondents did not receive training on how to use EIR, as opposed to forty-nine (33\%) who did. These percentages could influence the use of EIR. Emphasised as one of the highlights in the study conducted by Ollé and Borrego (2010) in Spain is the need to invest more efforts in helping users deal with the 
management of information, for it is detected that many users have difficulties accessing EIR. Therefore, the need for adequate knowledge about computers and retrieval techniques is desirable in order to use electronic resources effectively (Majid \& Abazova 1999). This idea is affirmed in the study by Janaki and Pauziaah (2007), which revealed that there are many postgraduates who are unsure about accessing and obtaining articles from databases.
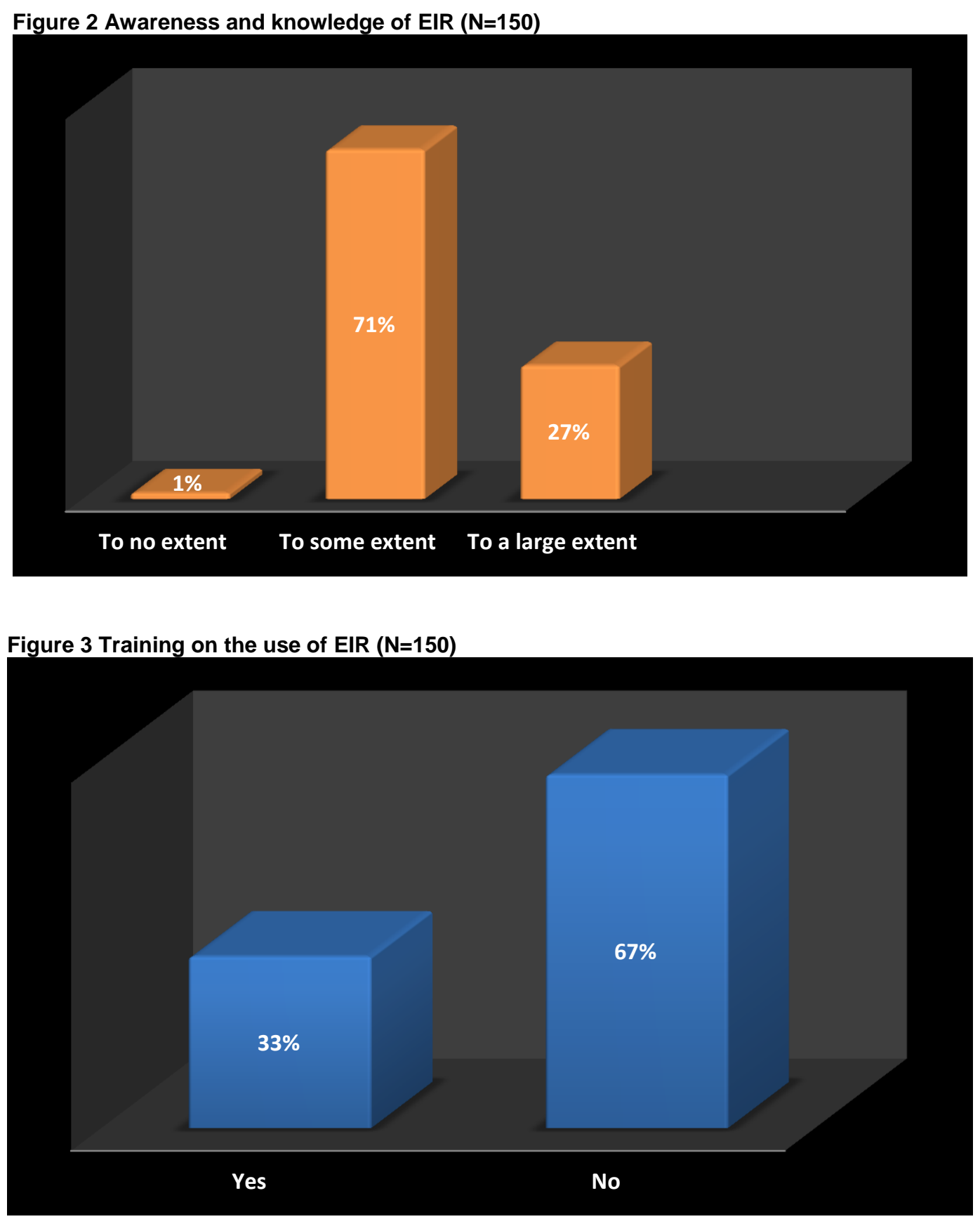

Although twenty-nine (19\%) respondents affirmed that EIR and services are fully functional in their institutional library, the majority of the respondents, that is, $121(81 \%)$, think that the current status of EIR and services at the institution is still at an introductory stage, while none of the respondents indicated that these resources are non-existent (Figure 4). According to Nnadozie and Nnadozie (2008), the availability of information resources and services does not automatically translate to information accessibility and use, thus what is yet to be determined is if the knowledge about the availability of EIR and services translates into their use for academic research by respondents.

In order to determine to what extent the postgraduate students use the EIR for academic research, they were asked about the purpose for which they use the internet. As shown in Figure 5, all respondents indicated "yes" for accessing databases and for e-mail purposes, and 119 (79\%) respondents indicated "yes" for social networking. This means that all respondents use the internet for research and for communication purposes. It is very encouraging to note that all respondents use the internet for the accessing of databases and e-mails. Golwal, Sonwane \& Vaishnav (2008) observe that electronic resources have become the most popular tools for research and academic activities.

The study conducted by Prabhavathi (2011) on information seeking behaviour of postgraduate students of Sri Padmavathi Mahila Visvavidyalayam, Tirupati, confirms that the internet is used mainly for research purposes (43\%) 
rather than for communication (18\%) or downloading programs (18\%). However, the other purpose for using the internet by the respondents was professional development $(11 \%)$, entertainment $(3 \%)$ and chatting $(1 \%)$. Therefore, it is not surprising to see that $100 \%$ of our respondents use the internet to gain access to EIR for research.
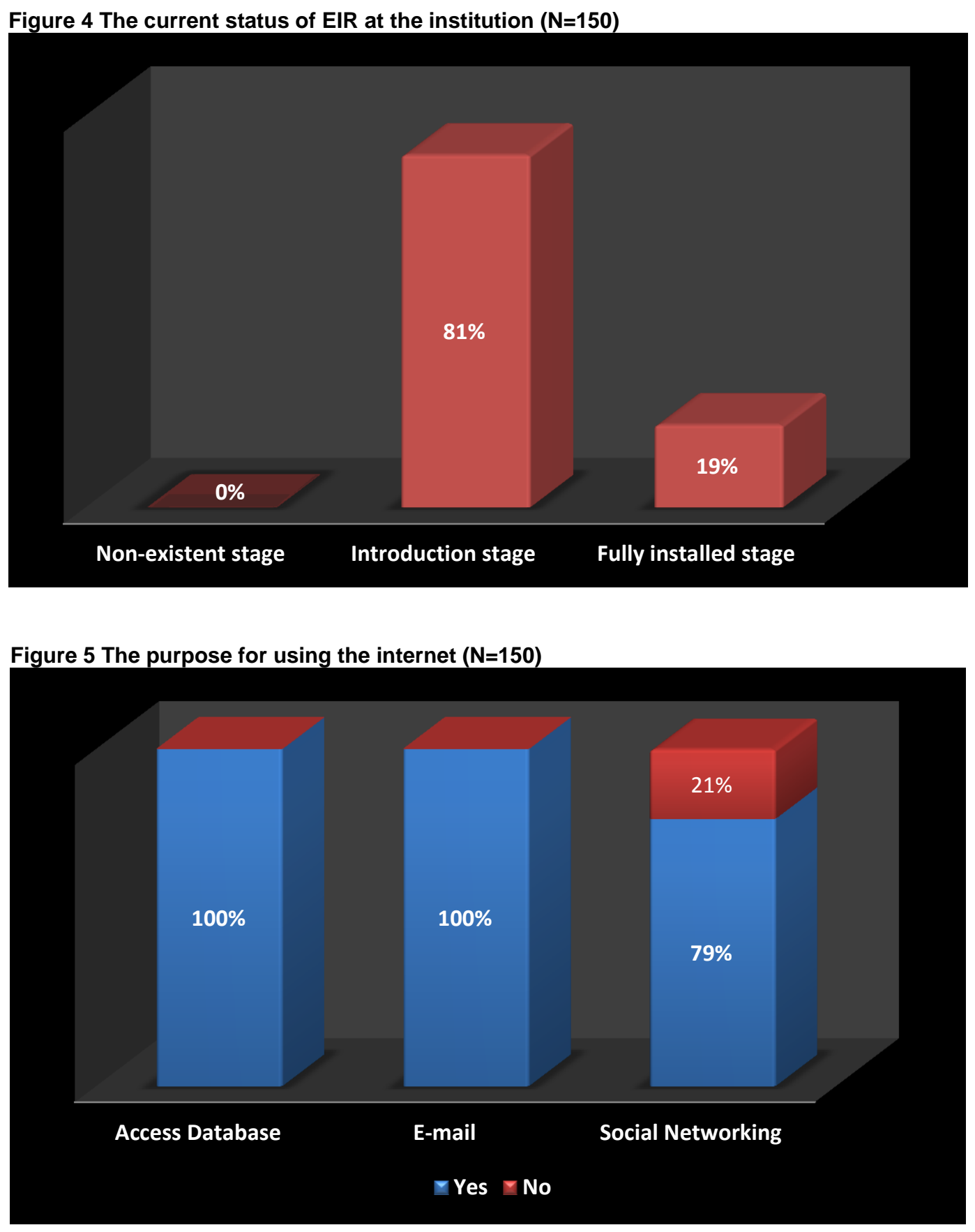

If the entire group of postgraduate students use the internet to access EIR for academic research, it is, therefore, also helpful to determine how often they use those resources. It is shown in Figure 6 that 106 (71\%) respondents indicated that they "often" use the internet, and a lower number of thirty-one (21\%) respondents indicated that they "always" use the internet and the fewest responses (8\%) came from those who indicated that they "rarely" use it. A survey conducted on emerging patterns and trends in utilising electronic resources in a higher education environment in Australia shows that electronic resources are used very frequently, with more than $59 \%$ of the respondents able to access them more than once a week (Deng 2010).

The results of the interviews showed that most respondents found a lack of training on the use of ICT in order to access EIR to be one of the major challenges of EIR use. The results of the questionnaire showed that out of 150 respondents, 107 did not receive any training. Consequently, postgraduate students find irrelevant information when queries are made using EIR, due to lack of training and therefore an inability to harness the various EIR effectively.

Other factors that were noted by the interviewees included the following: slow network speeds; low bandwidth; lack of space; insufficient ICT equipment; erratic power supply; and inaccessibility of some subscription-based materials. Alasa and Kalechukwu (1999) make observations about the state of the information network in Nigeria, which has serious 
consequences for the socio-economic development of the country, and that the inability of libraries to have access to current information needs to be looked into by the relevant stakeholders. Afolabi (2007) notes that "within the higher education in Nigeria, the libraries are far from up-to-date in resources; books, journals, abstracts and other collections are not current; there are gaps in sequence, which could be critical for knowledge generation and dissemination".

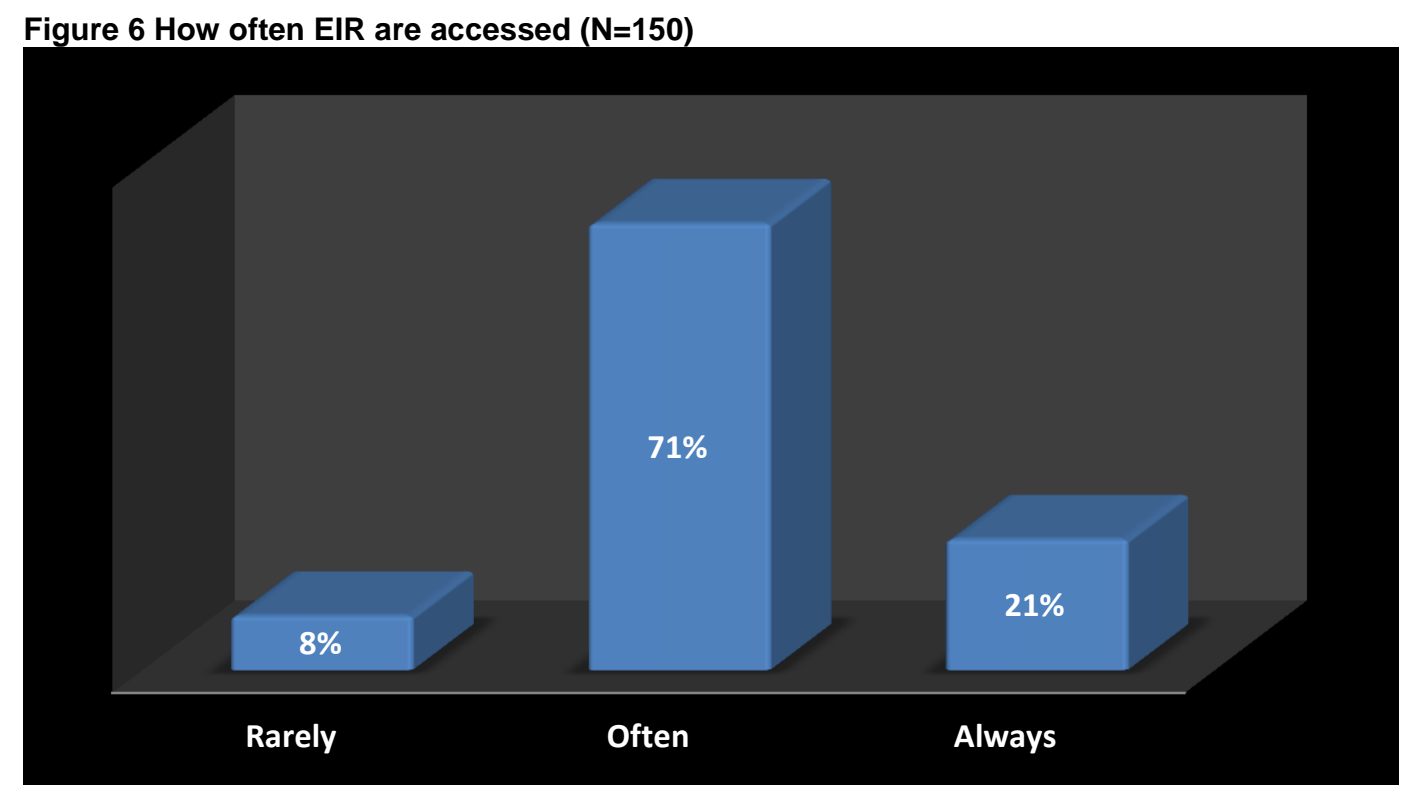

\section{Conclusion}

As observed from the literature reviewed, it is apparent that the use of EIR has a positive impact on academic research activities. However, despite the availability of EIR, the postgraduate students at the Delta State University, Abraka, lack training on how to access EIR to use them efficiently and effectively for academic research. It is important to emphasise that, in order to have effective access to the rapidly increasing number of EIR, students must acquire the necessary skills to find, select and use the different information resources. Orientation and training on the use of ICT and how to access the various databases should be extended to newly-registered students in every field of study at the institution. In addition, each faculty should be assigned a subject librarian.

Clearly, EIR provide a wide range of opportunities for postgraduate students and are easily accessible irrespective of time or place. The postgraduate students of the institution are aware of the various EIR even if their use is limited to the ones that are available and accessible in the institutional library. The institutional library should work jointly with the faculties to create awareness of EIR available in the library. In order to combat the problem of erratic power supply, there is a need for back-up generators. Furthermore, the library should have its own autonomous broadband internet server to enable users to have uninterrupted internet access. The institutional library should also develop an electronic institutional repository and encourage postgraduate students to use open access resources in order to manage and distribute information and knowledge, which will enhance access to and the sharing of vital information.

\section{References}

Adegbore, A.M. 2011. University faculty use of electronic resources: a review of the recent literature. $P N L A Q u a r t e r l y$, the official publication of the Pan Northwest Library Association, 75 (4). [Online]. http://www.academia.edu/3311720/ (17 October 2014).

Afolabi, M.O. 2007. Electronic Information for Libraries Network (Elfl.net) [Workshop notes]. Obafemi Awolowo University. 18 October.

Akpochafo, W.P. 2009. Revitalizing research in Nigerian Universities for national development. Educational Research and Review, 4 (5): 247-25.

Alasa, M. and Kalechukwu, I. 1999. Internet and academic library services development in Nigeria. Nigerian Libraries, 33(1): 17-35.

Ali, N. 2005. The use of electronic resources at IIT Delhi library: a study of search behaviour. The Electronic Library, 23(6): 691-700.

Ayoo, P.O. and Lubega, J.T. 2104. A framework for e-learning resources sharing (FeLRS). International Journal of Information and Education Technology, 4(1): 112-119.

Bako, S. 2005. Universities, research and development in Nigeria: time for a paradigmatic shift. Proceedings of the 11th General Assembly of CODESRIA, on Rethinking African Development: Beyond Impasse, Towards Alternatives. 6-8 December 2005.

Deng, H. 2010. Emerging patterns and trends in utilising electronic resources in higher education environment: an empirical analysis. New Library World, 111(3/4): 87-103. 
Dilek-Kayaoglu, H. 2008. Use of electronic journals by faculty at Istanbul University, Turkey: the result of a survey. Journal of Academic Librarianship, 34(4): 239-247.

Gardner, S.J, Juricek, J.C. and Xu, F.G. 2008. An analysis of academic libraries web pages for faculty. Journal of Academic Librarianship, 34(1): 16-24.

Golwal, M.D., Sonwane, S. and Vaishnav, A. 2008. Use of electronic journals in Dr. Babasaheb Ambedkar Marathwada University, Aurangabad: a case study. Proceedings of the 6th International Caliber-2008. 28-29 February \& 1 March 2008. Ahmedabad: INFLIBNET. 700-707.

Hamade, S. N. and Al-Yousef, S. 2010. The use of information resources by LIS graduate students in Kuwait. Library Review, 59(5): 360-369.

Hemminger, B.M., Lu, D., Vaughan, K.T.L. and Adam, S.J. 2007. Information seeking behaviour of academic scientists. Journal of the American Society for Information Science Technology, 58(14): 2205-2225.

Janaki, S. and Pauziaah, M. 2007. The use of subscribed online databases among the postgraduate at the University of Malaya Library. Proceedings of the International Conference on Libraries, Information and Society, ICOLIS 2007. 2627 June 2007. 257-263.

Ji, S.W., Michaels, S. and Waterman, D. 2014. Print vs. electronic readings in college courses: cost-efficiency and perceived learning. The Internet and Higher Education, 21: 17-24.

Kindilchie, A.I. and Samarraie, I.F. 2008. Interaction and impact of electronic information resources on Qatar University Faculty. Libri: International Journal of Libraries and Information Services, 58(4): 281-293.

Kont, K.R. 2010. Electronic scientific information in Estonia: cooperate and state financing of academic libraries. Journal of Inter-library Loan, Document Delivery and Electronic Reserve, 20: 83-101.

Liyi, Z. 2011. A survey of the use of electronic resources at seven universities in Wuhan, China. Electronic Library and Information System, 45(1): 67-77.

Majid, S. and Abazova, A.F. 1999. Computer literacy and use of electronic information resources by academics: a case study of International Islamic University, Malaysia. Asian Libraries, 8(4): 110 -111.

Ndinoshiho, H.M. 2010. The use of electronic information services by undergraduate nursing students at the University of Namibia's Northern campus: a descriptive study. Information Development, 26(1): 57-65.

Nnadozie, C.O. and Nnadozie, C.D. 2008. The information needs of faculty members in Nigerian private universities: a self-study. Library Philosophy and Practice (e-journal) [Online]. http://digitalcommons.unl.edu/cgi/viewcontent.cgi?article=1201\&context=libphilprac (8 April, 2011).

Okello-Obura, C. and Magara, C. 2008. Electronic Information access and utilization by Makerere students in Uganda. Library and Information Practice, 3(3): 39-56.

Okon, E.A. 2010. Internet access and use: a study of undergraduate students in three Nigeria universities. Electronic Library, 28(4): 555-567.

Ollé, C. and Borrego, A. 2010. Librarians' perception on the use of electronic resources at Catalan academic libraries: results of a focus group. New Library World, 111(1/2): 46-54.

Prabhavathi, D. 2011. Information seeking behaviour of post graduate students of SPMV, Tirupati (AP): a study. International Journal of Digital Library Services, 1(1): 34-38.

Rioux, K. 2014. Teaching social justice in an information literacy course: an action research case study. Qualitative and Quantitative Methods in Libraries (QQML). Special Issue: Social Justice, Social Inclusion. 23-30.

Tahir, M., Mahmood, K. and Shafique, F. 2010. Use of electronic information resources and facilities by humanities scholars. The Electronic Library, 28(1): 122-136.

Tella, A., Owolabi, K.A. and Attama, R.O. 2009. Student use of the library: a case study at Akanu Ibiam Federal Polytechnic, Unwana, Nigeria. Chinese Librarianship: an International Electronic Journal, $28: 5$.

Togia, A. and Tsigilis, N. 2009. Awareness and the use of electronic information resources by education graduate students: preliminary results from the Aristotle University Thessaloniki. Qualitative and Quantitative Methods in Libraries (QQML) International Conference, Chania Crete Greece. May 26-29, 2009.

Tyner, K. 2014. Literacy in a digital world: teaching and learning in the age of information. New York: Routledge.

Varghese, R.R. 2008. User studies in the electronic environment: review and brief analysis. The International Information and Library Review, 40: 83-93. 